\title{
Chemical composition determination of impurities and effect on the toxicity degree of solar panel components
}

\author{
Irina Vezhenkova $^{1, *}$, Margarita Semenova ${ }^{1}$, Alla Kovalevskaya $^{1}$, Artem Gryaznov ${ }^{1}$, M. Rocio Rodríguez-Barroso ${ }^{2}$, and \\ Rafael Jimenez Castañeda ${ }^{3}$ \\ ${ }^{1}$ Saint Petersburg Electrotechnical University "LETI", Environmental Engineering Department, Russia \\ ${ }^{2}$ Department of Environmental Technologies, Faculty of Marine and Environmental Sciences, Cadiz University , 11510, Puerto Real, \\ Cadiz, Spain \\ ${ }^{3}$ Renewable Energy Laboratory, Electrical Engineering Department. Engineering School of Engineering Cadiz University , 11510, Puerto \\ Real, Cadiz, Spain
}

\begin{abstract}
By 2050, according to the conclusion of the European Commission, the amount of solar panels waste will reach 78 million tons. $85 \%$ of all solar panels produced today belong to polycrystalline solar panels. The subject of this paper is the polymer components of polycrystalline solar panels EVA (ethyl vinyl acetate) and Tedlar ${ }^{\circledR}$ (polyvinyl fluoride). The paper reflects studies to determine the chemical composition of impurities of the solar panel components, and the degree of impurities influence on the toxicity of polymer components.
\end{abstract}

\section{Introduction}

Due to PV modules versatility, simplicity of installation and great respect for the environment, solar photovoltaic (PV) technology is positioned as one of the main sources of renewable energy with more installed electrical power both worldwide and in Europe. Currently, the International Renewable Energy Agency (IRENA) establishes that the world PV power installed in 2017 is $385 \mathrm{GW}$, where $28.46 \%$ belongs to Europe, when in 2000 only 815 MW were available and in 201039 MW. It is also considered a fast growing market, where according to different future scenarios, it is expected that in the year 2050 the PV will contribute from $2.5 \%$ to $25 \%$ of the global electricity demand [1].

Although PV technology is the most environmentally friendly technology of all energy and electricity generation technologies and one of the most popular sources of renewable energy, PV modules have a useful lifespan of approximately 30 years. [2].

With the enormous growth in the development and utilization of solar-energy resources, the proliferation of waste solar panels has become problematic. In addition, we have very little information on the PV-waste toxicity, low biodegradability and the huge landfill areas required [3].

Taking into account the proportion of elements that make up a PV module and that in 2017 the PV power installed in Europe was $109.48 \mathrm{GW}$, it is expected that by 2042 there may be around 10 million tons of crystalline silicon photovoltaic waste only in Europe; 7 million tons of glass, 977 thousand tons of aluminum, 962 thousand tons of polymers, 54 thousand tons of copper, 474 tons of silver, 11 thousand tons of tin, 11 tons of Zinc, 317 thousand tons of Silicon and 56 thousand tons of lead. [4].

In July 2012, the European Union formally revised the Waste Electrical and Electronic Equipment (WEEE) Directive, adding photovoltaic components as rejected electronic devices to be included in ten WEEE categories. Photovoltaic solar cells are now included in the electronic waste management system and must be collected and recycled [5].

\section{Materials and methods}

\subsection{Qualitative Analysis of PV-panels Polymer Components}

Qualitative analysis of the samples was carried out on a wave-dispersive X-ray fluorescence spectrometer SPECTROSKAN MAX after which the spectra were analyzed using the "Spectrum-Kvant" software.

Wave-dispersive X-ray fluorescence spectrometry allows you to determine the presence in a sample of a specific element or group of elements. Most often, it is supposed to search for foreign elements and impurities that should not be part of the sample.

In addition, wave-dispersive X-ray fluorescence spectrometry can detect a wide variety of items, even multiple items at the same time. This method is nondestructive, fast, highly effective and environmentally friendly. Also it can be used with various types of samples such as bulk, liquid, powder and gas. [6,7].

For devices with an evacuated spectrometric chamber, 4 different types of crystals are used - LiF200, C002, PET, KAP (or RAP). From the point of view of

* Corresponding author: smi-2409@yandex.ru 
qualitative analysis, they differ in the range of the recorded wavelengths and, accordingly, the determined elements. Table 1 shows the main elements that can be identified on each of the crystals[14].

Table 1. Identification of the main elements by X-ray fluorescence spectrometer.

\begin{tabular}{|l|l|}
\hline Crystal & \multicolumn{1}{|c|}{ Determined elements } \\
\hline LiF200 & K-series: Ti, V, Cr, Mn, Fe, Co, Ni, Cu, Zn, As, Br, \\
& Rb, Sr, Zr, Nb, Mo, Ga, Ge, Se, Sc, Nd, Ag, Cd, Sn, \\
& Sb, Cs, Pd \\
& L-series: Y, Ba, La, Ce, Pr, Sm, Eu, Gd, Tb, Dy, \\
& Ho, Er, Tm, Yb, Lu, Hf, Ta, W, Re, Os, Ir, Pt, Au, \\
& Hg, Tl, Pb, Bi, Th, Pa, Te, I, U \\
\hline C002 & K-series: $\mathrm{S}, \mathrm{Cl}, \mathrm{Ar}, \mathrm{K}, \mathrm{Ca}$ \\
& L-series: Ru, Rh, Pd, Ag, Cd, In, Sn, Sb, Te, I, Cs, \\
& Mo \\
\hline PET & K-series: $\mathrm{Si}, \mathrm{P}$ \\
& L-series: $\mathrm{Zr}, \mathrm{Nb}$ \\
\hline KAP & K-series: $\mathrm{Na}, \mathrm{Mg}, \mathrm{Al}, \mathrm{Si}$ \\
\hline
\end{tabular}

In our work to determine impurities of PV-panes polymeric waste we used LiF200 and C002 crystals.

\subsection{The chemotactic biotesting method}

A biotest analysis was chosen as a method for determining the toxicity degree of polymeric materials, as the one of the main methods for detecting environmental toxicity using test objects that shows danger, regardless of which substances and in what combinations changes in vital functions were caused test - organisms. [8].

For biotestesting we can use different test objects. In this study, Paramecium caudatum was chosen as a test object because are very close to higher animals and humans, which makes it possible to extrapolate data obtained in biotesting using ciliates per person [9-11].

The method for determining the toxicity of samples is based on the ability of test objects to respond to the presence of substances that are dangerous for their life activity in samples and to move directionally along the concentration gradient (in the direction of changing concentrations) of these substances (chemotactic reaction), avoiding their harmful effects [11].

If the test sample does not contain toxic substances, in the cuvette there will be a concentration of ciliates in the upper zone. The presence of toxic substances in the test sample leads to a different character of the redistribution of ciliates in the cuvette, namely: the higher the toxicity of the sample, the smaller the proportion of ciliates moves to the upper zone (the test sample). The biotest chemotactic technique is presented in Figure 1 [12].

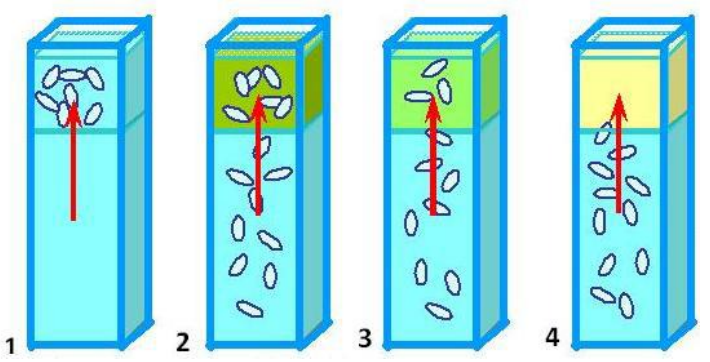

Fig. 1. Biotest chemotactic technique:1 - harmless sample; 2,3 - a sample of moderate toxicity; 4 - toxic test.

The toxic effect is a significant difference in the number of ciliates cells observed in the upper zone of the cuvette in the sample containing no toxic substances (control), compared with this indicator observed in the test sample (experiment).

A quantitative assessment of the test - reaction parameter characterizing the toxic effect is made by calculating the ratio of the number of ciliates cells observed in the control and the studied samples, and is expressed as a dimensionless quantity - the toxicity index $(\mathrm{T})$ [13].

\section{Research}

To determine the chemical composition of impurities of the solar panel components and its effect on the toxicity level of components sample preparation was carried out by the method of mechanical separation of the polycrystalline solar panels components. Disassembly includes the separation of the aluminum frame, cables, rear part and connection box of the PV sandwich panel, which is composed of polymers, semiconductor and glass. For disassembly, electric tools, heat guns, generalpurpose tools (screwdrivers, cutters, mallets, etc.) and personal protective equipment (gloves, masks, protective visor for electric grinder and protective glasses) were used.

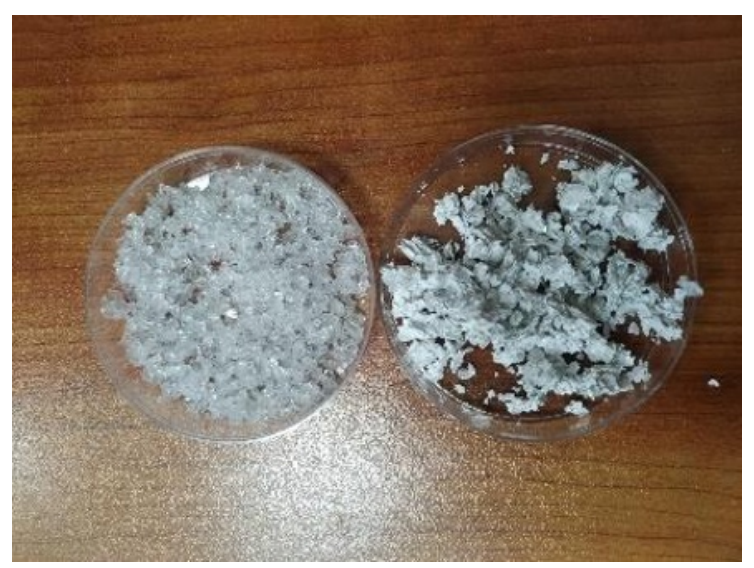

Fig. 2. Samples of waste polymer components EVA and Tedlar ${ }^{\circledR}$ of polycrystalline solar panels. 


\subsection{Determination of impurities of waste polymer components EVA and Tedlar}

In the work, analysis of the chemical composition of impurities was carried out in accordance with Qualitative Analysis Guide by Company "NPO" SPECTRON "(2017) [14].

The obtained samples (weighing 10 grams each) were analyzed on an X-ray fluorescence spectrometer SPECTROSKAN MAX using LiF200 and C002 crystals.

The results are presented in fig. 3 and 4.

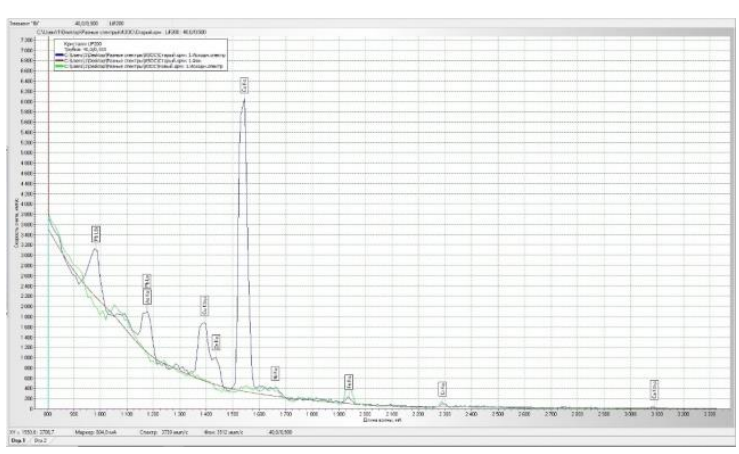

Fig. 3. Determination of impurities of waste polymer components EVA and Tedlar ${ }^{\circledR}$ of polycrystalline solar panels. Crystal LiF200 (green line is a control).

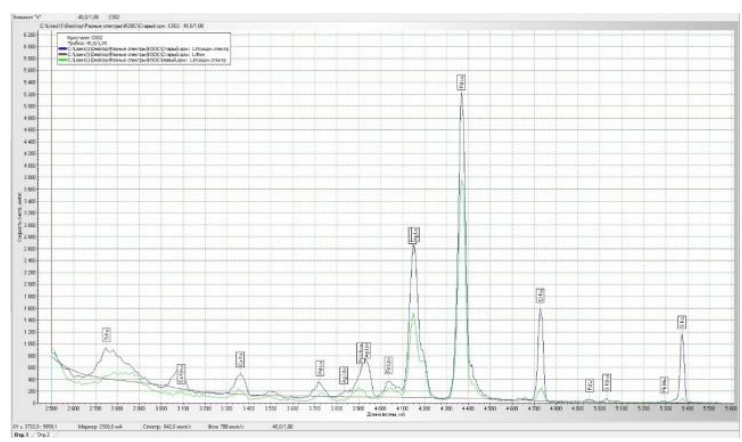

Fig. 4. Determination of impurities of waste polymer components EVA and Tedlar ${ }^{\circledR}$ of polycrystalline solar panels. Crystal C002 (green line is a control).

As can be seen from the spectrograms, polymer samples taken from the waste of solar panels contain impurities of $\mathrm{Ti}, \mathrm{Ca}, \mathrm{Ag}, \mathrm{Pd}, \mathrm{As}, \mathrm{Cl}, \mathrm{S}, \mathrm{Pb}, \mathrm{Zn} \mathrm{Cu}, \mathrm{Ni}$, $\mathrm{Fe}$. The last five elements are heavy metals.

According to GOST 17.4.1.02-83 for pollution control, 3 hazard classes of heavy metals and metalloids were identified: high-, moderate and low-hazard but most of the elements have not yet been assigned a hazard class [15].

Table 2. Hazard degree of heavy metals and metalloids.

\begin{tabular}{|l|l|}
\hline Danger degree & Elements \\
\hline High & $\mathrm{As}, \mathrm{Cd}, \mathrm{Hg}, \mathrm{Se}, \mathrm{Pb}, \mathrm{Zn}$ \\
\hline Moderate & $\mathrm{Co}, \mathrm{Ni}, \mathrm{Mo}, \mathrm{Cu}, \mathrm{Cr}, \mathrm{Sb}$ \\
\hline Small & $\mathrm{Ba}, \mathrm{V}, \mathrm{W}, \mathrm{Mn}, \mathrm{Sr}$ \\
\hline Unknown & $\mathrm{Ge}, \mathrm{Sn}, \mathrm{Ce}, \mathrm{La}, \mathrm{Bi}, \mathrm{Y}, \mathrm{Rb}, \mathrm{Cs}$, etc. \\
\hline
\end{tabular}

In accordance with the above regulatory document, at least 5 elements have moderate and high toxicity classes.

\subsection{Determination of the toxicity index of the test samples}

To study the degree of toxicity of EVA and Tedlar ${ }^{\circledR}$ polymers, obtained samples (weighing 2 grams each) of the studied components were mixed with distilled water (volume $50 \mathrm{ml}$ ), after which the resulting solution was mixed for several hours on the apparatus for shaking the liquid.

The concentration of ciliates in the cuvette was measured using the BIOTESTER 2M instrument, developed at the Department of Environmental Engineering at St. Petersburg Electrotechnical University "LETI". The device is intended to measure the spectral transmittance caused by moving microorganisms. The principle of operation is based on the natural features of ciliates moving up. (If the medium is not toxic, then a large number of individuals will emerge; if there is a toxicant, so the more the substance is toxic, then the smaller the number of ciliates will come up). Each of the test samples was analyzed in 3 cuvettes, 10 readings of the BIOTESTER-2M instrument were taken from each cuvette.

According to ERD F 16.3.16-10, to prevent gross errors during the analysis, the acceptability of the control sample was promptly evaluated according to the following inequality:

$$
\left|I k_{\max }-I k_{\min }\right| \leq 0,2 I_{a v . k}
$$

where $\mathrm{Ik}_{\max }$ - maximum readings of the device for control samples, $\mathrm{Ik}_{\min }$ - minimum readings of the device for control samples, $I_{\text {av.k }}$ - average readings of the device for control samples [16-19].

Assessment of the toxicity of the sample was carried out by the relative difference in the number of ciliates in the upper zone of the cuvette in the control and analyzed sample. In accordance with PND F T 16.3.16-10 the toxicity index is calculated by the formula:

$$
T=\frac{|I a v \cdot c-I a v \cdot s|}{I a v \cdot c} * K,
$$

where $I_{a v . c}$ - average readings of the device for control samples, $\mathrm{I}_{\text {av.s. }}-$ average readings for the test samples, $\mathrm{K}$ - coefficient of dilution of the sample (factor).

The toxicity index $\mathrm{T}$ is a dimensionless quantity and can take values from 0 to 1 in accordance with the degree of toxicity of the analyzed sample.

According to ERD F 16.3.16-10, depending on the value of the index, samples are classified according to their toxicity into 3 groups:

I. Acceptable toxicity $(0.00<\mathrm{T} \leq 0.40)$.

II. Moderate toxicity $(0.40<\mathrm{T} \leq 0.70)$.

III. High degree of toxicity $(\mathrm{T}>0.70)$.

When the toxicity index takes a value close to 1 , then such a study cannot unambiguously characterize the true level of toxicity of the sample. Then, the test sample should be diluted with distilled water or Lozin-Lozinsky medium so that the value of $\mathrm{T}$ does not reach 1 , and the resulting new index value is smart for the dilution coefficient. The sample is considered non-toxic, under the condition $\mathrm{T} \leq 0.40[16,20]$. 
The toxicity indices obtained as a result of mixing the solution with the test samples for 2 hours on the apparatus for shaking the liquid and the final values of the toxicity indices of the studied components presented are in Table 3.

Table 3. Toxicity indices of the studied components of polycrystalline solar panels.

\begin{tabular}{|c|c|c|c|c|}
\hline \multirow{2}{*}{$\begin{array}{c}\text { The } \\
\text { determined } \\
\text { indicator }\end{array}$} & $\begin{array}{c}\text { Test } \\
\text { substance }\end{array}$ & $\begin{array}{c}\text { Dilution } \\
\text { ratio }\end{array}$ & $\begin{array}{c}\text { Toxicity } \\
\text { index } \\
\text { (excluding } \\
\text { dilution } \\
\text { ratio) }\end{array}$ & $\begin{array}{c}\text { The degree } \\
\text { of toxicity of } \\
\text { the sample, } \\
\mathrm{T}\end{array}$ \\
\hline $\begin{array}{c}\text { Toxicity of } \\
\text { the sample at } \\
\text { the ciliates } \\
\text { Paramecium } \\
\text { caudatum }\end{array}$ & EVA & 1 & $0.012 \pm 0.001$ & $\begin{array}{c}\text { Acceptable, } \\
\mathrm{T} \leq 0.40\end{array}$ \\
\cline { 2 - 3 } & Tedlar & 1 & $0.029 \pm 0.002$ & $\begin{array}{c}\text { Acceptable, } \\
\mathrm{T} \leq 0.40\end{array}$ \\
\hline
\end{tabular}

To study toxicity in detail we use Paramecium caudatum, a series of experiments were carried out to determine the dependence of the change in the degree of toxicity on the dissolution time of the components. The following time intervals were considered as control time points: 24 hours, 48 hours, 96 hours and 7 days (168 hours) - as the most used time intervals in methods for determining the toxicity of the environment using infusoria [16-20]. You can read more about these studies in a previously published the article [8].

According to the research the toxicity indices increase if the polymer components are in significant time in solution, thereby approaching the value that characterizes the toxic environment.

\section{Conclusion}

In the course of the work, it was revealed that the polymer components waste of solar panels contains 12 impurities of various elements, including 5 elements have moderate and high toxicity classes (As, $\mathrm{Cd}, \mathrm{Hg}, \mathrm{Se}$, $\mathrm{Pb}, \mathrm{Zn}, \mathrm{Co}, \mathrm{Ni}, \mathrm{Mo}, \mathrm{Cu}, \mathrm{Cr}, \mathrm{Sb})$.

The toxicity indices of EVA and Tedlar components increase with prolonged exposure of materials in aqueous solution, approaching the values characterizing the unsafe degree of toxicity for the environment and human health. Graphs reflecting the obtained dependence are built. These studies show the need to develop a methodology for the disposal and reuse of solar panel components, preventing possible negative consequences for the environment and human health. In the future, it is planned to carry out a quantitative elemental analysis of the samples and continue the study of the degree of toxicity of the components to reveal a more accurate dependence of the change in the degree of toxicity on time.

\section{References}

[1] A. Zuser, H. Rechberger, Considerations of resource availability in technology development strategies: The case study of photovoltaics, Resources, Conservation and Recycling 56, 1, 5665 (2011)
[2] Keiichi Komoto, Jin-Seok Lee, End-of-Life Management of Photovoltaic Panels: Trends in PV Module Recycling Technologies, IEA PVPS Task12, Subtask 1, Recycling, Report IEA-PVPS T12-10 (2018)

[3] Yan $\mathrm{Xu}$, Jinhui Li, Quanyin Tan, Anesia Lauren Peters, Congren Yang, Global status of recycling waste solar panels: a review, Waste Management 75, 450-458 (2018)

[4] J.K. Choi, V. Fthenakis, Environ. Design and optimization of photovoltaics recycling infrastructure, Sci. Technology 44, 22, 8678-8683 (2010)

[5] Study on photovoltaic panels supplementing the impact assessment for recast of the WEEE directive, Bio intelligence service, Final report (2011)

[6] Min Yao, Dongyue Wang, and Min Zhao, Element Analysis Based on Energy-Dispersive X-Ray Fluorescence, Advances in Materials Science and Engineering, 290593, 1-7 (2015)

[7] N.V. Alov, Total reflection X-ray fluorescence analysis: Physical foundations and analytical application (A review), Inorg Mater 47, 1487-1499 (2011)

[8] M. Semenova, I. Vezhenkova, M. Stepanova, T. Kustov, Determination of the degree of toxicity of EVA and Tedlar polymers during the disposal of components of crystalline solar panels, E3S Web of Conferences 161, 01085 (2020)

[9] G.A. Tihanovskay, Y.V. Mashihina, Biological environmental control (VoGU, Vologda, 2016)

[10] C.M. Chesnokova, N.V. Chugai, Biological methods of estimating quality of environmental objects (Publishing House Vladim. state University, Vladimir, 2008)

[11] D.B. Gelashvili, V.S. Bezel, M.E. Bezrukov, E.B. Romanova, A.A. Silkin, A.A. Nizhnygorodzev, Principles and methods of environmental toxicology (Publishing House of Nizhny Novgorod State University, Nizhny Novgorod, 2015)

[12] A.G. Bubnov, S.A. Buymova, A.A. Gushchin, T.V. Izvekova, Biotest analysis - an integrated method for assessing the quality of environmental objects (GOU VPO Ivan. state chemical technol. un-t, Ivanovo, 2007)

[13] N.L. Izmailova, O.A. Lyashenko, I.V. Antonov, Biotesting and bioindication of the state of water bodies (SPbGTURP, St. Petersburg, 2014)

[14] Qualitative Analysis Guide by Company «NPO» SPECTRON (2017)

[15] GOST 17.4.1.02-83 Nature Conservation (SSOP), Soils, Chemical classification for pollution control (2008)

[16] ERD F 16.3.16-10, The methodology for determining the toxicity of production and consumption waste by the express method using the Biotester series device (2015) 
[17] Russian National Standard, Water, Determination of toxicity by survival of freshwater ciliates Paramecium caudatum Ehrenberg, 57166-2016 (2016)

[18] Guidelines for the application of bioassay methods to assess the quality of water in drinking water supply systems, MR No. TsOS PV R 005-95

[19] ERD F 16.3.12-07, The methodology for determining the toxicity of ash and slag waste by biotesting based on the survival of paramecium and ceriodaphnia, Federal number FR.1.39.2007.04104, soil science faculty of Moscow State University and OJSC All-Russian Thermotechnical Institute

[20] ERD F 14.1:2:3.13-06, ERD F 16.1:2.3:3.10-06, Methodology for determining the toxicity of wastes, soils, sewage, surface and groundwater sediments by biotesting using equidimensional ciliates Paramecium caudatum Erenberg, Federal number FR.1.39.2006.02506, LETAP, Moscow State University 